\title{
Sigilo profissional: quando revelar?
}

Recebido em: 12/01/2011

Aceito em: 14/04/2011
Ramone Aparecida Przenyczka'

Maria Ribeiro Lacerda ${ }^{2}$ Rita de Cássia Chamma ${ }^{3}$

Considerando que a confidencialidade das informações do paciente é uma constante na prática dos profissionais da área da saúde, objetivou-se, neste artigo, realizar uma reflexão teórica sobre o sigilo profissional na enfermagem com o auxílio de mapas conceituais. A análise do atual Código de Ética dos Profissionais de Enfermagem mostrou que a regra geral aponta para a não-revelação do segredo. Porém, essa regra admite exceções, que devem ser analisadas conjuntamente com outras normas da legislação brasileira, como o Código Penal e o Código Civil. Como consideração final, ressaltam-se a necessidade de atualização e a conscientização sobre o tema.

Descritores: Ética, Legislação de Enfermagem, Privacidade, Comunicação Sigilosa.

\section{Professional confidentiality: when to reveal?}

Whereas the confidentiality of patient information is a constant practice of health professionals, we intend, in this article, perform a theoretical reflection on professional secrecy in nursing with the aid of concept maps. The analysis of the current Code of Ethics for Professional Nursing showed that the general points for not revealing the secret. However, this rule admits exceptions that should be considered together with other requirements of legislation such as the Brazilian Penal Code and Civil Code. As a final consideration, we emphasize the need for updating and developing awareness on the issue.

Descriptors: Ethics, Legislation of Nursing, Privacy, Confidentiality.

\section{Confidencialidad profesional: cuando revelar?}

Considerando que la confidencialidad de la información del paciente es una práctica constante de profesionales de la salud, el objetivo en este artículo fue realizar una reflexión teórica sobre el secreto profesional en enfermería con el uso de mapas conceptuales. El análisis del actual Código de Ética para los Profesionales de Enfermería mostró que la norma general es no revelar un secreto. Sin embargo, esta regla admite excepciones que deben ser considerados junto con otros requisitos de la legislación brasileña como el Código Penal y el Código Civil. Como consideración final, es necesario la actualización y la conciencia de los profesionales sobre el tema.

Descriptores: Ética, Legislación de Enfermería, Privacidad, Confidencialidad.

\section{INTRODUÇÃO}

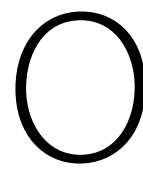
s diferentes profissionais da área da saúde possuem diversas obrigações de natureza ética. Essa é compreendida como a disciplina filosófica que estuda os sistemas morais, criados pelos homens para compreender o porquê das normas e de suas proibições, além de explicar seus pressupostos ${ }^{(1)}$.

$\mathrm{Na}$ terminologia da técnica profissional, a ética é o vocábulo usado para designar a soma de deveres que enuncia a norma de conduta do profissional no desempenho de suas atividades e em suas relações com as pessoas com quem possa ter trato. A ética estabelece a pauta das ações e é fundada em normas estabelecidas pelos usos e costumes, mas pode ser instituída pelos órgãos que dirigem e fiscalizam a profissão(2).

Nesse contexto, há uma questão ética na atenção à saúde bastante presente na prática dos profissionais, qual seja, a confidencialidade, aquilo que é secreto ou segredo. É comum e, às vezes, até necessário pacientes e seus familiares revelarem informações pessoais durante algum atendimento. Assim, fazem parte do sigilo profissional todos esses dados, bem como aqueles adquiridos por meio de outros profissionais, de exames e de prontuários físicos ou eletrônicos.

O segredo profissional baseia-se na ciência de fatos que chegam ao conhecimento da pessoa em razão da profissão que exerce e cuja revelação possa ocasionar danos àquele a quem o segredo pertence ${ }^{(2)}$. Ademais, o segredo respeita a privacidade e funda-se numa relação de confiança entre o sujeito que conta seu segredo e a pessoa para quem ele contou ${ }^{(3)}$. E, no âmbito da saúde, essa relação dá segurança para o paciente revelar à equipe de saúde situações potencialmente embaraçosas ${ }^{(4)}$.

Um estudo que objetivou identificar como usuários do Sistema Único de Saúde (SUS) esperam que os profissionais de saúde se comportem quando um dos parceiros de casal heterossexual tem sífilis mostrou, entre outros resultados, que o profissional é visto como um mediador da situação de revelação de diagnóstico ao parceiro e alguém de quem esperam orientação e apoio no momento de falar a verdade ${ }^{(5)}$.

1 Enfermeira. Advogada. Mestranda do Programa de Pós-Graduação em Enfermagem da Universidade Federal do Paraná (UFPR). Membro do Núcleo de Estudos, Pesquisa e Extensão em Cuidado Humano de Enfermagem (Nepeche). E-mail: przenyczka@yahoo.com.br.

2 Enfermeira. Doutora em Filosofia em Enfermagem. Coordenadora do Nepeche da UFPR. Coordenadora do Mestrado em Enfermagem da UFPR. Professora Adjunta da UFPR.

3 Enfermeira. Doutora em Enfermagem. Conselheira do Conselho Federal de Enfermagem. Professora visitante do Programa de Pós-Graduação de Enfermagem da UFPR. 
Outra pesquisa, que discutiu situações que envolvem o sigilo das informações de mulheres portadoras do HIV no Programa Saúde da Família (PSF), indicou a necessidade de acolhimento e vínculo para a abertura da privacidade. $\mathrm{O}$ acolhimento deve fazer parte do atendimento das usuárias dos serviços de saúde para que se sintam seguras em abrir sua privacidade ao profissional, o que pode auxiliar no planejamento das ações pertinentes a suas questões de saúde ${ }^{(6)}$. Disso depreende-se a importância do papel do enfermeiro durante a busca de informações do paciente e sua revelação a outrem.

Isso posto, o objetivo deste texto é realizar uma reflexão teórica sobre o sigilo profissional na enfermagem com o auxílio de mapas conceituais.

\section{LEGISLAÇÃO SOBRE SIGILO PROFISSIONAL}

$\mathrm{O}$ atual Código de Ética dos Profissionais de Enfermagem (Cepe) - Resolução Cofen (Conselho Federal de Enfermagem) $311 / 2007$ possui cinco artigos que tratam do sigilo profissional. Seu art. 82 traz como dever dos profissionais "manter segredo sobre fato sigiloso de que tenha conhecimento em razão de sua atividade profissional, exceto casos previstos em lei, ordem judicial ou com o consentimento escrito da pessoa envolvida ou de seu representante legal" (7:82).

Como se vê, a regra geral é não revelar o segredo. Outras disposições previstas na legislação brasileira, como, por exemplo, o Código Penal Brasileiro, define no art. 154 o crime de violação do segredo profissional quando "revelar a alguém, sem justa causa, segredo de que tem ciência em razão de função, ministério, ofício ou profissão e cuja revelação possa produzir dano a outrem"(8:558). A pena, nesse caso, é de detenção de três meses a um ano ou multa ${ }^{(8)}$.

O Código Civil Brasileiro, por sua vez, informa, no art. 229, que "ninguém pode ser obrigado a depor sobre fato cujo respeito, por estado ou profissão, deva guardar segredo"(9:166). O Código de Processo Penal, igualmente, dispõe, em seu art. 207, que "são proibidas de depor as pessoas que, em razão da função, ministério, ofício ou profissão, devam guardar segredo, salvo se, desobrigadas pela parte interessada, quiserem dar seu testemunho"(10:635).

No entanto, a regra geral de não revelar segredo possui exceções, como vista no art. 82 do Cepe. A primeira delas diz respeito aos casos previstos em lei, como é exemplo quando ocorre um crime (mapa conceitual 1).

Mapa conceitual 1 - Revelação de segredo profissional à autoridade competente

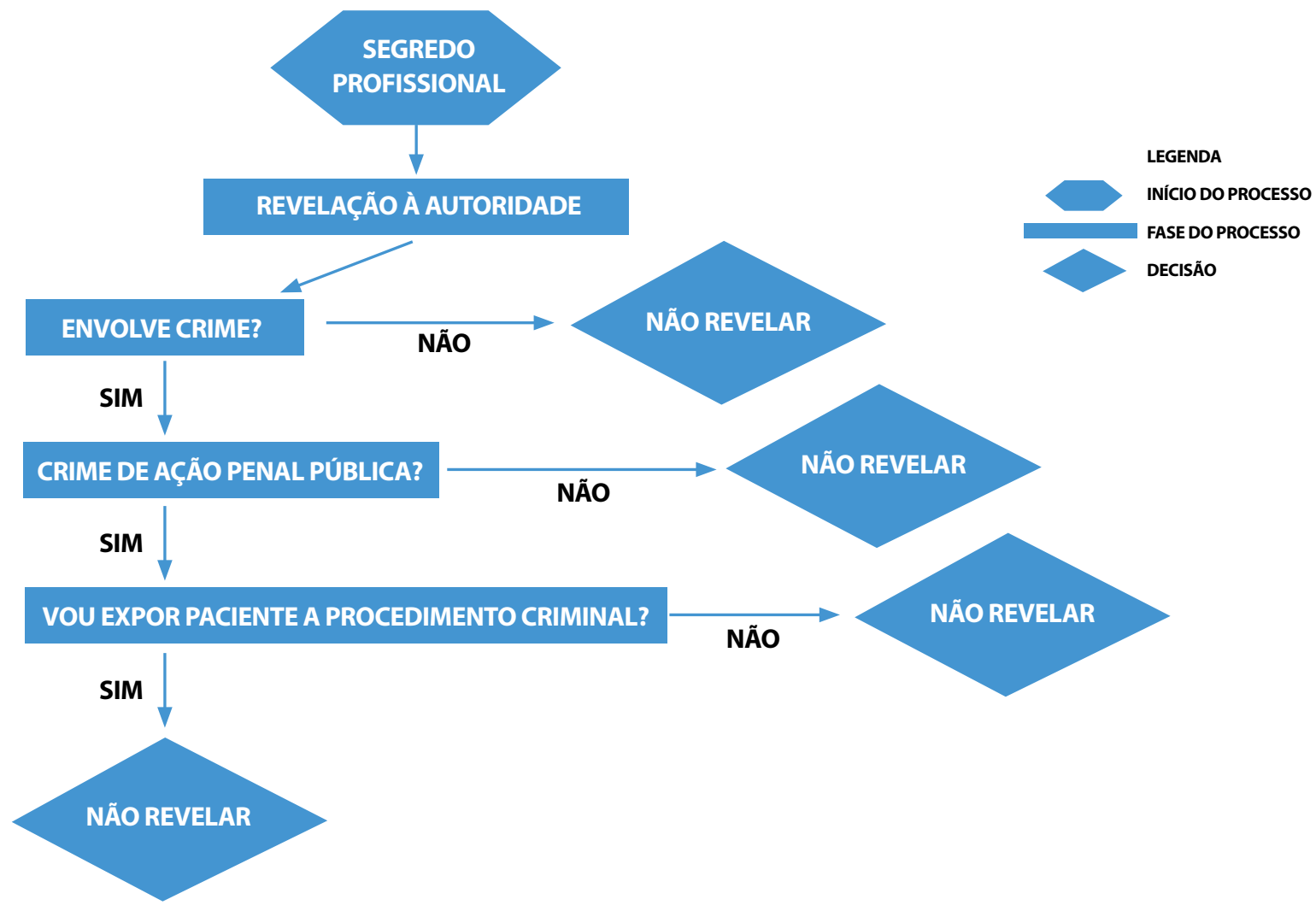


Um crime deve ser comunicado quando o paciente não for exposto a procedimento criminal, como determina o art. $66 \mathrm{da}$ Lei das Contravenções Penais(11:605), segundo o qual é crime de omissão de comunicação do fato quando o profissional deixar de relatar à autoridade competente "crime de ação pública, de que teve conhecimento no exercício da medicina ou de outra profissão sanitária, desde que a ação penal não dependa de representação e a comunicação não exponha o cliente a procedimento criminal". A pena para seu descumprimento é multa ${ }^{(11)}$.

O sigilo pode ser quebrado se o crime é de ação pública que não dependa de representação, ou seja, aquela que não necessita da reclamação da vítima. Todavia, não se pode esquecer que $o$ paciente não deve ser exposto a procedimento criminal. Essas duas condições devem ser respeitadas simultaneamente.

Outra exceção contida na lei, e que permite a revelação, é o art. 269 do Código Penal, que dispõe como omissão de notificação de doença "deixar o médico de denunciar à autoridade pública doença cuja notificação é compulsória"(8:570). E, embora mencione somente o médico, esse dever cabe aos demais profissionais da área da saúde ${ }^{(3)}$. A pena é de detenção de seis meses a dois anos e multa ${ }^{(8)}$.

Mais uma exceção está compreendida na lei 8069/90 Estatuto da Criança e do Adolescente, que exige a revelação de casos de suspeita ou confirmação de maus-tratos contra criança ou adolescente ao Conselho Tutelar ${ }^{(12)}$. O mesmo ocorre em casos de abuso de cônjuge ou de familiar contra o idoso(13).

Como visto, o Cepe admite a revelação de segredo por ordem judicial. No entanto, essa permissão vai de encontro aos arts. 229 do Código Civil e 207 do Código de Processo Penal, já analisados, que devem ser cumpridos. Portanto, a regra é não revelar segredo profissional nem por ordem judicial. O Código de Ética dos Profissionais de Enfermagem explica essa ressalva e esclarece, no art. 82 , $\S 3^{\circ}$, que "o profissional de enfermagem intimado como testemunha deverá comparecer perante a autoridade e, se for o caso, declarar seu impedimento de revelar o segredo"(7:82).

Ainda, no caput do art. 82, há outra exceção, que permite a divulgação de segredo com o consentimento da pessoa envolvida, o que corrobora o Código de Processo Penal. E, mesmo no falecimento do envolvido e fato de conhecimento de todos, o profissional não deve revelar o segredo ${ }^{(7)}$.

A Resolução Cofen $311 / 2007$, outrossim, no art. 82 , $\$ 2^{\circ}$, afirma que "em atividade multiprofissional, o fato sigiloso poderá ser revelado quando necessário à prestação da assistência"(7:82) (mapa conceitual 2).

Mas, de todas as menções feitas no Cepe sobre esse

Mapa conceitual 2 - Revelação de segredo profissional à equipe multiprofissional

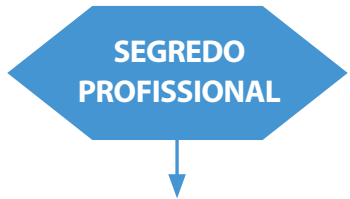

REVELAÇÃO À EQUIPE (CEPE, art. 82, § 2)

$\downarrow$

É INDISPENSÁVEL À ATIVIDADE

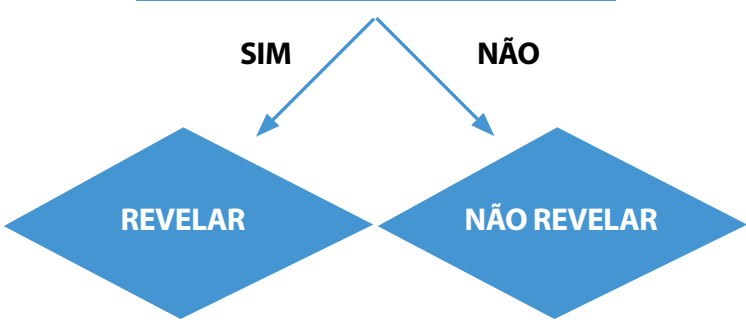

LEGENDA

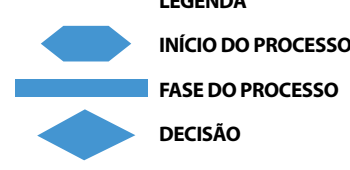


Mapa conceitual 3 - Revelação de segredo profissional ao responsável pelo menor de idade

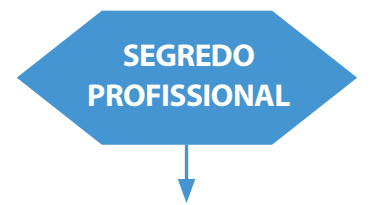

REVELAÇÃO AO RESPONSÁVEL (CEPE, art. 82, § 4)
TEM CONDIÇÕES DE SEGUIR O TRATAMENTO, COM DISCERNIMENTO, SOZINHO?

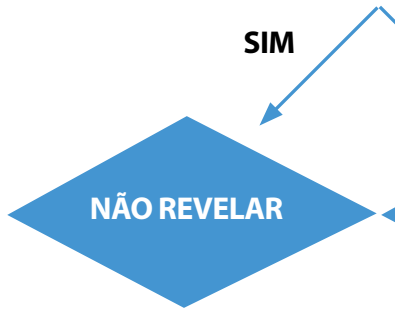

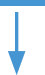

\section{É MENOR DE IDADE?}
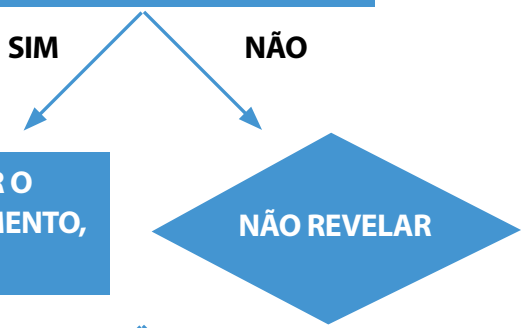

NÃO

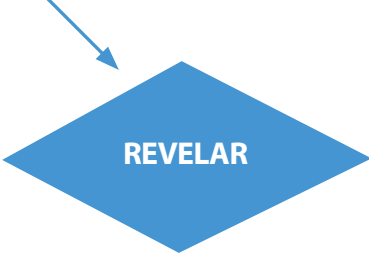

assunto, talvez a mais inovadora seja a que está inserida no $\S 4^{\circ}$ do art. 82 , que trata do segredo relativo ao menor de idade: "O segredo profissional referente ao menor de idade deverá ser mantido, mesmo quando a revelação seja solicitada por pais ou responsáveis, desde que o menor tenha capacidade de discernimento, exceto nos casos em que possa acarretar danos ou riscos ao mesmo"(7:82) (mapa conceitual 3).

A Resolução Cofen 311/2007 mostra a responsabilidade do enfermeiro ao determinar, no art. 83, que é seu dever"orientar, na condição de enfermeiro, a equipe sob sua responsabilidade, sobre o dever do sigilo profissional"(7:82). E, por fim, o Cepe traz mais duas proibições: não se pode franquear o acesso a informações relativas à assistência, a não ser que a legislação permita, tampouco divulgar situações identificando os envolvidos ${ }^{(7)}$.

\section{CONSIDERAÇÕES FINAIS}

Os enfermeiros adquirem, diariamente, informações sigilosas dos pacientes sob seus cuidados, sendo que, infelizmente, há casos de revelação indevida de tais informações. Ressalta-se a necessidade de os profissionais de enfermagem manteremse atualizados sobre as regras que circundam sua profissão e, mais especificamente, sobre a questão do segredo.

Esta reflexão pretendeu esclarecer as disposições realizadas pelo atual Cepe, assim como sua relação com as demais normas previstas na legislação brasileira que tratam, igualmente, do segredo profissional. Ressalta-se que tão premente quanto sua leitura para a devida atualização é a conscientização de sua importância no contexto da prática profissional.

\section{Referências}

1. Figueiredo AM. Ética: origens e distinção da moral. Saúde Ética Justiça. 2008;13(1):1-9.

2. Ribeiro RFG. A ética profissional dos procuradores públicos: o sigilo profissional. Rev Dir. 2005;8(10):13-9.

3. Fortes PAC. Ética e saúde. Questōes éticas, deontológicas e legais. Autonomia e direitos do paciente. Estudo de casos. São Paulo: Pedagógica e Universitária; 1998.

4. Loch JA. Confidencialidade: natureza, características e limitaçōes no contexto da relação clínica. Bioética. 2003;11(1):51-64.

5. Pisani JP, Zoboli ELCP. Doenças sexualmente transmissíveis: preservar a confidencialidade do marido ou proteger a saúde da mulher? Cogitare Enferm. 2009;14(3):476-83.

6. Abdalla FTM, LYI Nichiata. A abertura da privacidade e o sigilo das informaçōes sobre o HIV/Aids das mulheres atendidas pelo Programa Saúde da Família no município de São Paulo, Brasil. Saúde Soc. 2008;17(2):140-52.

7. Resolução 311 de 08 de fevereiro de 2007 (BR). Aprova a reformulação do
Código de Ética dos Profissionais de Enfermagem. Diário Oficial da União, Brasília, 13 fev. 2007. Seção 1, p. 81-83.

8. Código Penal. In: Pinto ALT, Windt MCVS, Céspedes L, colaboradores. Vade mecum. 9a ed. São Paulo: Saraiva; 2010. p. 513-600.

9. Código Civil. In: Pinto ALT, Windt MCVS, Céspedes L, colaboradores. Vade mecum. 9a ed. São Paulo: Saraiva; 2010. p. 128-335.

10. Código de Processo Penal. In: Pinto ALT, Windt MCVS, Céspedes L, colaboradores. Vade Mecum. 9a ed. São Paulo: Saraiva; 2010. p. 607-710. 11. Decreto-lei 3688, de 3 de outubro de 1941 (BR). In: Pinto ALT, Windt MCVS, Céspedes L, colaboradores. Código Penal: Constituição Federal e legislação complementar. 16a ed. São Paulo: Saraiva; 2010. p. 150-9.

12. Lei n॰ 8069 , de 13 de julho de 1990 (BR). Estatuto da criança e do adolescente. In: Pinto ALT, Windt MCVS, Céspedes L, colaboradores. Vade mecum. $9^{a}$ ed. São Paulo: Saraiva; 2010. p. 1049-78.

13. Lei n॰ $10741 / 2003$ (BR). Estatuto do idoso. In: Vade Mecum RT. $5^{a}$ ed. São Paulo: Revista dos Tribunais; 2010. p. 1017-23. 